\title{
Analysis of A Conceptual Framework of John Holland's Theory of Career Satisfaction
}

\author{
Kaur Ramandeep ${ }^{1}$, Patheja Surjit Kaur², Bajwa Amandeep Kaur ${ }^{3}$ \\ ${ }^{1}$ Principal, Ajit Nursing Institute, Sunam, Punjab, India, ${ }^{2}$ Director of Education, DBU, Mandi Gobindgarh, Punjab, \\ India, ${ }^{3} H O D$ Mental Health Nursing, SGRDU, Amritsar, Punjab, India
}

\begin{abstract}
This article aims to propose the conceptual framework of John Holland's Theory of Career Choice for faculties of university. This model achieves the requirements of a college where it covers every one of the critical variables which assist the colleges with expanding the work fulfillment through surveying the character attributes of resources and empower their maintenance after determination for a specific post. The examination is finished by considering different parts of character characteristics like extroversion, principles, receptiveness, neuroticism and a survey of the past writing pertinent to the investigation, especially nearby RIASEC as outlined character attributes to give new bits of knowledge towards incredible occupation fulfillment in resources of college. This paper proposes six measurements in particular practical, analytical, creative, social, and venturesome. It is cheerful that this structure would perceive the best character characteristic towards improving the work fulfillment among resources of colleges.
\end{abstract}

Key words: Job satisfaction, personality traits, John Holland's Theory, Conceptualframework, conscientiousness, openness, neuroticism

\section{Introduction}

Every nation needs to have sound teachers at each level to strengthen nation's young population but higher educational teachers are playing vital role in this direction. As per UGC annual report of year 2018-19 in India total of 1416299 university level teachers are working on varying capacity among that 819283 were reported male and rest 597016 are female teachers. In this number the major bulk 862101 are designated as assistant professors which is the entry point in university academic organizational structure. Out of total strength of teachers, in Punjab, total of 51575 university level teachers are working out of which 20871 are male and remaining 30704 are female teachers. Punjab falls at second stage among women percentage of teachers in state after Kerala. These statistics are clearly showing the

\footnotetext{
Corresponding Author:

Kaur Ramandeep

Principal, Ajit Nursing Institute, Sunam, Punjab, India

Email-ramandeep1972@yahoo.com
}

importance that these university teachers job satisfaction has to take up at priority by keep in mind the future of youth in state and India. ${ }^{1}$

Personality is the most important trait of a person to define the individual as well as creating individual difference in his behaviour. Personality traits think about fundamental measurements which individuals' contrast. ${ }^{2}$ Though there are various instruments which helps to assess the personality traits but a big five inventory is one among all widely accepted to define the individual characteristic. These five qualities are openness, conscientiousness, extroversion, agreeableness and neuroticism. ${ }^{3}$

Openness qualities known as creative mind and insightful thought, conscientiousness characteristic incorporate elevated levels of mindfulness, great motivation control, and objective coordinated behaviours, agreeableness characters are rich in trust, selflessness, graciousness, fondness, neuroticism is a characteristic portrayed by misery, crankiness, and 
passionate shakiness and extraversion is described by volatility, amiability, garrulity, confidence, and high measures of passionate expressiveness. ${ }^{4}$

Job satisfaction has been characterized as "emotions or full of feeling reactions to features of the (working environment) circumstance".Job satisfaction is likewise accepted to be dispositional in nature. ${ }^{5}$ This dispositional perspective expects that estimating individual attributes can help in the expectation of occupation satisfaction. The dispositional wellspring of Job satisfaction has been bolstered by contemplates that show solidness in Job satisfaction, both after some time and over various circumstances. ${ }^{6}$ Minnesota Satisfaction Questionnaire (MSQ, 1966) 20 items short version is one of widely utilized research tool to evaluate the job satisfaction of professionals at three levels like intrinsic, extrinsic and general category. ${ }^{7}$

The intrinsic satisfaction counted by the way how people think about the job they do, the extrinsic satisfaction counted by the way how employees feel about the job benefits, pay and other segments of their job whereas the general satisfaction is combination of these two. ${ }^{7}$

A conceptual framework is an assortment of interrelated ideas, similar to a hypothesis yet not really so very much worked-out. A hypothetical structure guides research, figuring out what things being a specialist we will quantify, and what factual connections we are search for, specifically the present study. ${ }^{8 \& 9}$

At the point when analyst structures a system for their investigations then the endeavour will be on distinguishing all the potential ideas and what will be connection among to keep the investigation on track. As such, we can say that hypothetical system will give a skeleton to scientists to the investigation.Job satisfaction and personality traits have been investigated by various researchers on various samples like factory workers, telecom workers, hospital employees with different approach of assessing personality traits and job satisfaction. When we talk about correlation among these two factors then one area of educations seems most appropriate to study and that is teachers.
Researcher attempted here to visualize to identify and settle the concepts of John Holland theory among carrier choice of university/college teachers. As we all realized over the period of time the level of job satisfaction of teachers not only helps to create quality student's outcome but also enhance the level of creativity among themselves and their students. The present paper kept an objective to analysis of John Holland theory model to understand its implication for carrier satisfaction in relation with teacher's personality characteristics.

\section{Material and Methods}

This paper informing an analysis report of John Holland theory model utilization for creating a job satisfaction conceptual skeleton by considering university teachers individual personality characteristics. To create this analysis report, the researcher searched in-depth about John Holland theory model and for this researcher attempted to search printed and electronic data base such as ProQuest, Embase, PsycARTICLES, EBSCO, ResearchGate, EORTC, Scopus, Educational Resources Information Centre (ERIC), and Allied Health Literature (CINHAL). The existing literatures were very systematically opted to recruit into this analysis document.

\section{Inclusion Criteria}

- The research paper only which directly belongs to John Holland theory model.

The paper which is easily accessible online and full text available.

The studies which are completed in English language.

Articles included from the year 2000 to 2020 .

\section{Exclusion Criteria}

- The study has no keyword as John Holland theory model.

\section{Poor quality journal publications.}

- The research study which is published in without ISSN number journals. 
- The research studies which are not available on journal database.

The research studies in which only abstract is available. language.

- The studies which are published in local

\section{Result and Discussion}

Researcher strongly believes that the existing Holland theory would be very ideal to explain the concept of correlation in between personality traits and job satisfaction, in which researcher explained concepts to express the impact of personality traits on job satisfaction among university teachers.

Professions are controlled by a cooperation between our character and the earth in John Holland's Theory of Career Choice. This hypothesis fit most in light of the fact that Holland affirms that individuals of a similar personality type cooperating in work make a situation that fits and rewards their sort. Inside this hypothesis, there are six essential kinds of workplace, which connect straight forwardly to the character types. Holland underscores that individuals who decide to work in a domain like their character type are bound to be effective and fulfilled. This thought is significant as it shows Holland's hypothesis can be adaptable, joining mix types.

Holland's hypothesis takes a critical thinking and psychological way to deal with profession arranging. His model has been extremely compelling in profession guiding. It has been utilized through well-known evaluation apparatuses. John Holland's Theory of Career Choice (RIASEC) keeps up that in picking a profession, individuals lean toward occupations where they can associate with other people who resemble them. They look for conditions that will let them utilize their aptitudes and capacities, and express their mentalities and qualities, while taking on charming issues and jobs. Conduct is controlled by a communication among character and condition.
The RIASEC model has been concentrated broadly corresponding to a wide assortment of develops, for example, birth request, relational conduct, capacity to profit by self-improvement medicines for sorrow, and sex-job direction.

Holland's hypothesis is focused on the idea that the vast majority fit into one of six personality types:

1. Realistic

2. Investigative

3. Artistic

4. Social

5. Enterprising

6. Conventional.

1. Realistic: This is considered as Doers.

2. Investigative: In theory it represented as thinkers.

3. Artistic: as its word meaning clear that it known as creator

4. Social: social personality reflects character of helping, so it known as Helper.

5. Enterprising: It is said as persuader. Enterprising occupations much of the time include beginning and completing activities.

6. Conventional: These kind of personality people are considered as organizer.

Analysis of John Holland model to reflect on correlation in between personality traits and job satisfaction:

University teacher carries mixture of different personalities at various levels to bring out expected learning outcome, hence this theory as a whole describing as follows in relation with their job satisfaction. This theoretical framework has been shown in figure-1. 


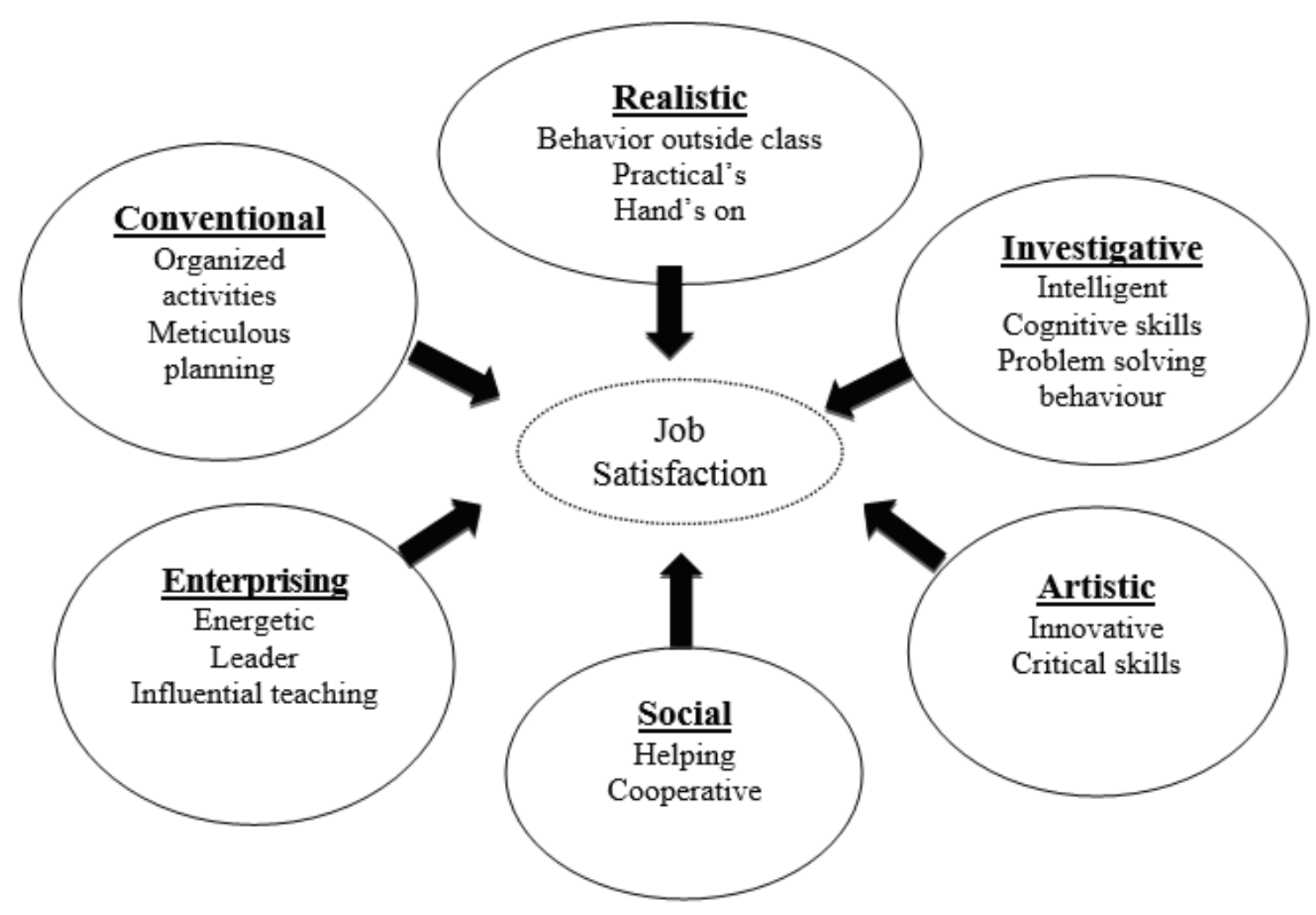

Figure-1: Holland theory application

1. Realistic: Higher educational teachers or university teachers are performing their job of imparting learning. Students are observing them at all point of time irrespective of their presence in within class or outside class, at formal or informal place. Teachers are observed outside classes as well. One of important skill of every teacher to create hands on training session or say practical sessions. Teachers regularly manage students learning. This all make them real Doers.

2. Investigative: Teachers is considered as an intellectually brave profession. Facing high number with different intellectual calibre students is a regular job of teacher. University teacher do reflect qualities of their cognitive skills, intelligence and problem-solving behaviour to students. These qualities make them constant thinkers.

3. Artistic: It is expected form each higher education educators to inculcate culture of creativity. Teacher not only practicing but also make their student learn about creativity, innovation and critical skills. When teachers practice such characters then it assumed based on this theory that teachers will get confidence to handle their work with much more quality and also improves their communications skills. This character establishes them as Creator.

4. Social: Teacher is a profession which always practice on the theme of equal opportunity, means teacher never discriminate among anyone. Basically, this quality empowers them to create a helping and cooperative in their all engagements. Second important part that teachers working in university do come across in connection with other stakeholders as well which includes like parents and community leaders, which will also keep them engaging in cooperation and helping. This quality often named them as Helper. This is most important character as per Holland theory which is important for teacher's profession.

5. Enterprising: Every teacher in higher study institution shows quality to lead. College students are at 
the age of 18 plus are consider as early mature and they supposed to be managed by university teachers, and this practice developed them as a good leader. These teachers developed habit to lead by their influential teaching and their energetic behavior. By leading the learners in all that way make them persuader.

6. Conventional: Honest speaking parents and teachers are the only two kind of people who teach us about way to develop our managerial skills and organizing capacity. When it came to university level then teacher is the best person to teach the students about meticulous planning and organized activities. This character of teacher made them good administrator along with planned organizer.

Therearequitea few quality studies have also reflected on same issue such as Manikandaprabu et al (2017) distributed their examination paper impact of personality traitson job satisfactionamong telecom representatives. Specialists expected to decide the connection between personality traitsand job satisfactionamong telecom workers. A cross sectional investigation completed to address the examination objective. The authors have identified the John Holland theory model to express the relationship among personality traits and job satisfaction among telecom workers. ${ }^{10}$

Kamarul Zaman Bin Ahmad et al (2018) distributed in their examination of Hierarchical atmosphere and job satisfaction: do workers' characters make a difference? Study intended to give a few bits of knowledge on the transaction of hierarchical atmosphere and job satisfaction, accepting character attributes as a mediator. Creators audits the surviving writing from which it builds up a hypothetical model which is then tried exactly in the Malaysian setting, utilizing progressive relapse technique. The outcomes infer that there are directing impacts of character qualities on the connection between specific parts of authoritative atmosphere and occupation fulfilment. ${ }^{11}$

Mary Agnes et al (2017) led and distributed their exploration work of Pioneer personality traits and representative job satisfaction in the media part, Kenya. Current investigation meant to decide the impact of pioneer personality traits on worker job satisfaction. The examination utilized an illustrative exploration configuration to build up the reason impacts between pioneer character characteristics and worker job satisfaction. Way objective hypothesis and Big Five-factor model of personality traits supported the investigation. Survey was utilized to get information relating to the models develops. The examination demonstrated that pioneer extraversion; receptiveness to new encounters; enthusiastic dependability; reliability and suitability effect sly affect representative job satisfaction. The examination in this way presumed pioneers who depict extraversion; receptiveness to new encounters; passionate solidness; scruples and appropriateness improve worker job satisfaction. ${ }^{12}$

All in all, the idea of John Holland Theory is about promoting performance of faculties by enhancing their job satisfaction and advocating stakeholders' participation in selection and retention of the faculties by recognizing the personality traits.

\section{Conclusion:}

Present paper intended to forecast the critical analysis of John Holland model to understand the university teacher's carrier satisfaction in relation with their personality traits. The model much suits to explain this relationship among job satisfaction and their personality traits as concepts of personality traits among university teachers helps them to satisfy with their jobs. As indicated by Holland, employees are not survivors of their surroundings but rather effectively look for possibly perfect workplaces. In the event that a person's personality and the workplace fit, at that point the individual will appreciate the work and create and develop in the job and sense of job satisfaction will appear.

Acknowledgement: Researcher would like to acknowledge untried support and guidance of Desh Bhagat University.

Ethical Clearance: Taken from Ethical Committee, Desh Bhagat University, Mandi Govindgarh, Punjab via Ref. No.: DBU/RC/421-A.

Source of Funding: Self-funded project 
Conflict of Interest: Nil

\section{References}

1. Commission UG. UGC Annual Report 2018-19. 2019.

2. Compton MJ. The Relationship Between Personality Traits and Career Satisfaction of Front-Line Retail Workers Submitted by Mary J . Compton A Dissertation Presented in Partial Fulfillment of the Requirements for the Degree Doctorate of Psychology Grand Canyon Universi. Grand Canyon University; 2019.

3. Mount M, Ilies R, Johnson E. Relationship of personality traits and counterproductive work behaviors: The mediating effects of job satisfaction. Pers Psychol. 2006;59(3):591-622.

4. Kendra Cherry. The Big Five Personality Traits [Internet]. Personality Psychology. 2020. Available from: https://www.verywellmind.com/the-big-fivepersonality-dimensions-2795422

5. Rukh G, Dang J, Olivo G, Ciuculete DM, RaskAndersen M, Schiöth HB. Personality, lifestyle and job satisfaction: causal association between neuroticism and job satisfaction using Mendelian randomisation in the UK biobank cohort. Transl Psychiatry. 2020;10(1).

6. Cook al. Job satisfaction and job performance: is the relationship spurious?Graduate Studies of
Texas A\&M University. Graduate Studies of Texas A\&M University; 2008.

7. Martins H, Proença MT. Minnesota satisfaction questionnaire: psychometric properties and validation in a population of portuguese hospital workers. Investig e Interv em Recur Humanos. 2014;(3).

8. Kent KN. The relationships between personality traits, vocational interest themes, and college major satisfaction. 2008; 1 electronic text (81 p.)

9. Ayeni A. Impact of Holland' s Personality Typology on Job Performance Among Selected Nurses in the South - West of Nigeria. 2016;24(January):28-32.

10. M M, Sundaramoorthy J, Pandey V. Influence of Personality Traits on Job Satisfaction among Telecome Employees. Int J Manag Soc Sci Res Reveiw. 2017;1(36):297-302.

11. Ahmad, K. Z. Bin, Jasimuddin, S. M., \& Kee, W. L. (2018). Organizational climate and job satisfaction: do employees' personalities matter? Management Decision, 56(2), 421-440. https://doi.org/10.1108/ MD-10-2016-0713

12. Kiarie, M.A.W., Maru, L.C. and Cheruiyot, T. K. (2017). Leader personality traits and employee job satisfaction in the media sector, Kenya. TQM Journal, 29(1), 133-146. https://doi.org/https://doi. org/10.1108/TQM-09-2015-0117 